Military Technical College Kobry El-Kobbah, Cairo, Egypt.

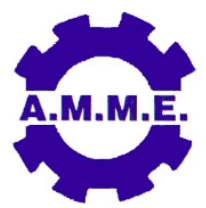

\title{
A REVIEW ON FORMABILITY PREDICTION AND CONISTITUVE DAMAGE MODELS OF SHEET FORMING OF MAGNESIUM ALLOYS
}

\author{
M. Farouk ${ }^{1}$ and M. Mohamed ${ }^{2,3}$
}

\begin{abstract}
In recent years, the demand for using magnesium (Mg) alloys has significantly increased in several industrial fields. Due to their favorable strength/weight ratio thus Mg alloy demonstrating a valid replacement for aluminum alloys and High Strength Steels particularly for the production of lightweight parts in aerospace and automotive industries. However the formability of $\mathrm{Mg}$ at cold forming conditions is significantly poor and determination of the material formability need special testing procedures and understanding of material failure mechanism. FLD is commonly used to characterize the formability of materials and the key feature of FLD is the forming limit curve (FLC). This paper provides a review on the determination of strain-based and stress-based forming limit diagrams is introduced in this paper. In addition, the constitutive damage models for predicting and characterizing the forming limits of magnesium alloy sheet metals under a wide range of forming conditions at both industrial and scientific level.
\end{abstract}

\section{KEYWORDS}

Magnesium (Mg) alloys; Forming limit diagram (FLD); Formability test, Damage Model.

1 Teaching Assistant, Dept. of Mechanical Engineering, Helwan University, Helwan, Egypt.

2 Advanced Forming Research Centre (AFRC), Strathclyde University, Glashow, UK.

Corresponding Author: Dr. Mohamed Mohamed; Tel: +44141 534 5510, Mob.:

+447712155969, Email: Mohamed.mohamed@strath.ac.uk and

Web: www.strath.ac.uk/afrc.

3 Mechanical Engineering Department, Faculty of Engineering, Helwan University, Egypt. 


\section{INTRODUCTION}

As it is well known magnesium is considered as the lights structural metal; it also has good heat dissipation, good electromagnetic shield and good damping. However As mentioned previously, formed sheet magnesium components are not viable as formability is very low due to the limited number of slip-systems in the hexagonal-closepacked (HCP) crystal structure available for plastic deformation. It was reported that a fine grain structure in Mg-alloys enhances strength and improves ductility by promoting the operation of non-basal slip systems and restricting twinning.

Taking into account that the intermediate forming/annealing cycles largely eliminated most of the twins and prevent the build-up of dislocations and that there was a significant amount of new grain boundaries, including twin boundaries, generated in the material. Consequently, the strength is enhanced and the ductility is improves.

Mg alloy sheets characterized by poor plastic behavior at room temperature due to its HCP crustal structure, offering that only basal slip planes are active. The critical resolved shear stress (CRSS) for non-basal slip planes (prismatic or pyramidal planes) are higher than that for basal slip planes, which is the reason for only basal planes are active at room temperature [1]. The (CRSS) of non-basal planes decreased by increasing temperature offering more slip planes and higher formability.

To make Mg alloys meet its impatience's for structural manufacturing, the magnesium sheet must retain higher ductility which can be achieved through grain refinement and reducing of basal texture development during deformation, besides higher temperature deformation.

Since coarse grain cause cracking at grain and twin boundaries, the fine grain (grain refinement) reduces twining (Mukai et al. [2]), also shows non-basal dislocation at room temperature and reducing the critical resolved shear stress introducing increased formability.

During Mg sheet rolling production the basal texture are introduced parallel to the sheet surface which makes $\mathrm{Mg}$ sheets have poor formability, as deformation take place parallel to basal planes [1]. So the reduction of basal texture development increasing formability of $\mathrm{Mg}$ sheets alloy.

Temperature has the greatest influence on $\mathrm{Mg}$ sheets formability, as at high temperature twining eliminated and more slip systems are introduced so ductility improved. The great effect of temperature on the formability of $\mathrm{Mg}$ alloys has been investigated by many researchers.

A critical survey on the determination of strain-based and stress-based forming limit diagrams is introduced in this paper. In addition, the constitutive damage models for predicting and characterizing the forming limits of magnesium alloy sheet metals under a wide range of forming conditions at both industrial and scientific level. 


\section{REVIEW ON FLDS AT COLD, WARM AND HOT CONDITION FOR MAGNESIUM ALLOYS}

Forming Limit Diagram (FLD) illustrates the critical combination of major and minor surface strains in a sheet metal at the onset of necking failure. Material condition, tool features, process variables can be optimized via identifying the information from the FLD. Keeler [3] and Goodwin [4], who established the concept of FLDs in which the relationship between the surface principal strains, $\varepsilon_{1}$ and $\varepsilon_{2}$, at fracture is established. This relationship is presented as a curve and if the orthogonal principle strain set, at all positions in a deforming sheet, lies below this curve, it is no failure occurred in product and if above, failure will occur.

There are several factors such as sheet thickness (Fatmaoui et al., 2008) [5], strain hardening exponent (Djavanroodi and Derogar [6]), strain rate and grain size (Kröhn et al.[7]), and temperature (Palumbo et al. [8]) affect the FLD.

Many researchers have studied and provided different mathematical models for predicting FLDs. Vallellano et al. [9] studied the formability of $1.2 \mathrm{~mm}$ AA2024-T3 sheet subjected to biaxial stretching using a hemispherical punch. In Vallellano's work, several classical ductile failure criteria (integral and local) were embedded in ABAQUS in order to predict FLDs numerically. They concluded that a local criterion, particularly Tresca's criterion, provides a better prediction for failure, than does the integral criteria.

Wang [10] has provided an experimental and numerical investigation of the anisotropic effect on the formability for Mg alloys sheets metal (AZ31B, ZEK100) at worm/hot forming condition. In Wurong's work, the ductility for samples at $45^{\circ}$ rolling direction is higher than the ductility at $90^{\circ}$ rolling direction.

In addition of Wang' work, Aravindha [11] developed forming limit diagram for AZ31B and ZEK100 Mg alloy sheets at elevated temperature (from $250^{\circ} \mathrm{C}$ to $450^{\circ} \mathrm{C}$ for AZ31B and from $300^{\circ} \mathrm{C}$ to $450^{\circ} \mathrm{C}$ for ZEK100) and strain rates $\left(10^{-3}\right.$ and $\left.10^{-2} \mathrm{~s}^{-1}\right)$, Aravindha suggests that $250^{\circ} \mathrm{C}-300^{\circ} \mathrm{C}$ will be appropriate temperature for manufacturing complex $\mathrm{Mg}$ components. Also according to Aravindha's work there is no change in forming limits for both materials when strain rate increases from $\left(10^{-3}\right.$ to $\left.10^{-2} \mathrm{~s}^{-1}\right)$ at fixed temperature, so recommended the use of faster strain rate $\left(10^{-2} \mathrm{~s}^{-1}\right)$. However Chan [12] concludes experimentally and analytically that the formability of AZ31B magnesium alloy sheet increase with temperature rise and with decreasing strain rate Also the formability is increased with increasing strain rate sensitivity (m-value).

\section{Forming Limit Diagram at Cold Forming Condition}

The Methods of the Determination of FLD at Cold Condition are the Nakajima test (uses a hemispherical punch) and the Marciniak test (uses a flat punch) as shown in Fig.1.

The AZ31B Mg Alloy Sheets seems to have poor formability at temperature of $25^{\circ} \mathrm{C}$ as indicated by the forming limit diagram shown in Fig. 2, this low ductility because of the Hexagonal Close-Packed (HCP) crustal structure as mentioned before which offering 
only two deformation mechanism systems the basal and twinning systems at room temperature $[20,23]$.

Lingyun [15] shows that the AZ31B Mg alloy hot-rolled sheets have higher forming and processing capacity than that of the cold rolled sheets at room temperature.

\section{Forming Limit Diagram at Warm and Hot Forming Condition}

The experimental tests performed by Kim [14] to obtain Forming Limit Diagram (FLD) of AZ31B Mg alloy sheets at different temperatures of up to $300^{\circ} \mathrm{C}$ are introduced using die set with a hemispherical punch and heating cartridges were inserted in the die and punch shown in Fig. 3, enabling heating of the die set and blank to the required temperature (Isothermal condition). The test specimens were cut in the rolling direction with a $0.5-\mathrm{mm}$-thickness. Tests were performed at different temperatures and at a constant punch speed of $0.1 \mathrm{~mm} / \mathrm{s}$.

To visualize only the temperature effect other formability affecting parameters maintained constant, (for example strain rate (punch speed), strain hardening exponent $(n)$, rolling direction, and sheet thickness).

During the warm forming condition (at temperature $100^{\circ} \mathrm{C}, 200^{\circ} \mathrm{C}$ and $250^{\circ} \mathrm{C}$ ) The forming limits are remarkably increased, throughout these formation condition (usually from $200^{\circ} \mathrm{C}$ to $300^{\circ} \mathrm{C}$ ) the ductility of $\mathrm{Mg}$ sheet increases due to more slip systems are activated (non-basal slip systems such as prismatic and pyramidal systems), alloying for higher formability [23] shown in Fig. 4.

The forming limit are increased slightly, during hot forming of $\mathrm{Mg}$ sheet at temperature equal or higher than $300^{\circ} \mathrm{C}$ (generally from 0.3 to 0.5 from melting temperature) shown in Fig. 5, there are microstructure change, including recrystallization and grain growth. The hot forming process improves ductility of the blank to achieve more formability. The FLC0 of the AZ31B sheet reached a value seven times that at room temperature at $300{ }^{\circ} \mathrm{C}[10,11,14]$.

\section{Forming Limit Diagram for AZ31B Mg Alloy Sheets at Different Temperature}

The higher the forming temperature the higher the forming limit (increased formability) The forming limit increased sharply with temperature up to $200^{\circ} \mathrm{C}$, due to the activation of the sliding planes; and thereafter, there is no much increase in forming limit shown in Fig. 6. The range from $200^{\circ} \mathrm{C}$ to $300^{\circ} \mathrm{C}$, the commonly used range of forming temperatures for magnesium alloy sheets [14].

\section{Forming limit diagram for AZ31B at $(200,250,300){ }^{\circ} \mathrm{C}$ and punch speed $(0.1 \mathrm{~mm} / \mathrm{s}$, $1 \mathrm{~mm} / \mathrm{s}$ )}

Ambrogio [16] indicates in his paper that Formability increased as temperature raised as shown in Fig. 7, but declined by increasing punch speed from .1 mm/s to $1 \mathrm{~mm} / \mathrm{s}$ at $300^{\circ} \mathrm{C}$ as shown in Fig. 8, Such altitudes are related to the microstructural evolution, that is highly affected by temperature and strain rate due to the occurrence of grain boundary sliding, dynamic recrystallization and grain growth. The forming limit diagram 
shown in Fig. 9, obtained from the rolling direction specimens represents formability higher than that obtained in the transversal one; however transverse direction specimens have a higher drawability [17].

\section{Forming limit diagram for rare earth-magnesium alloy ZEK100 sheet at different temperature}

The forming limit data of ZEK100 Mg alloy sheets shown in Fig. 10, reveals a great formability dependence upon temperature. At $300^{\circ} \mathrm{C}$, ZEK100 has shown significant anisotropy between the rolling and transverse sheet direction (the transverse direction having better formability than the rolling direction) This behavior is consistent with observations by Kurukuri et al. [18] who found that RD tensile samples exhibit higher strength with less work hardening and elongation compared to the transverse direction $[19,20]$.

\section{DAMAGE CONSTITUTIVE MODELS}

The deterioration of a metallic structure during plastic and viscoelastic deformation is due to nucleation, growth and coalescence of the internal defects such as micro voids and micro cracks. This process is generically termed as damage. Damage has a significant effect on the mechanical properties of a metal during deformation. The internal defects in the material act as nucleation sites and induce damage (Mohamed [21]). The evolution of damage is essentially related to the dominant deformation mechanism. This mechanism depends on the deformation temperature, strain rate, material microstructure and chemical composition. Different deformation mechanisms are associated with different damage types. These various damage types are discussed below (Mohamed [21]).

\section{Creep Type Damage}

Creep is the permanent plastic deformation of a metal under static load for a prolonged period of time. Creep phenomenon is usually observed at high temperatures $\left(0.3 T_{m}<\right.$ $\left.T<0.5 T_{m}\right)$. The static creep load is generally below the yield stress of the material, and the rate of the deformation is relatively low (Hayhurst and Dyson [22]).

According to Cocks and Ashby [28], any type of structural change resulting from adverse creep deformation can lead to damage. The creep damage can be of the forms: i) voiding or cracking at a microscopic level or ii) microstructure deterioration at a microscopic level (Ashby and Dyson [22]). They suggested that voids grow by various controlled mechanisms such as power-law creep, grain-boundary diffusion or, a combination between both.

Kachanov [24], described the creep damage process using the damage state variable, $\mathrm{D}$, in which the material is treated as a continuum as seen in Equation (1) (Liu [26]):

$$
\dot{\mathrm{D}}=\left(\frac{\sigma_{\mathrm{e}}}{\mathrm{A}_{\mathrm{d}}}\right)^{\mathrm{m}_{\mathrm{d}}} \cdot(1-\mathrm{D})^{-\mathrm{n}}
$$

where $A_{d}, m_{d}, n$ are material constants. 
For a constant stress creep condition, the damage variation with time can be determined by simple integration of Equation (1).

Cocks and Ashby [28] established a model (spherical hole within isolated cylinder) based on the spherical cavities shape doesn't change during their growth [28]. At time $\mathrm{t}=\mathrm{t}_{\mathrm{n}}$ cavities at grain boundary initiate, at time $\mathrm{t}=\mathrm{t}_{\mathrm{c}}$ they coalescence. According to the void growth and creep strain rate the following equation have been introduced [27].

$$
\frac{\mathrm{df}_{\mathrm{h}}}{\mathrm{d}_{\mathrm{t}}}=\mathrm{g}\left[\frac{1}{\left(1-\mathrm{f}_{\mathrm{h}}\right)^{\mathrm{n}}}-\left(1-\mathrm{f}_{\mathrm{h}}\right)\right] \dot{\varepsilon}_{\mathrm{ss}}
$$

where $\dot{\varepsilon}_{\mathrm{ss}}$ the steady creep rate without cavities, $\mathrm{f}_{\mathrm{h}}$ the cavity area fraction, $\mathrm{n}$ is material constant and $\mathrm{g}$ is defined as:

$$
g=\sinh \left\{2 \frac{\mathrm{n}-\frac{1}{2}}{\mathrm{n}+\frac{1}{2}}\left(\frac{\sigma_{\mathrm{m}}}{\bar{\sigma}}\right)\right\}
$$

where $\bar{\sigma}$ the von mises equivalent stress, $\sigma_{\mathrm{m}}$ the hydrostatic stress.

In the presence of mobile dislocation damage, the secondary and tertiary creep can be modeled (Lin et al. [24]). Lin, et al., represented a damage model as follow:

$$
\dot{\mathrm{D}}=\mathrm{C}_{\mathrm{d}}(1-\mathrm{D})^{2} \cdot \dot{\varepsilon_{\mathrm{e}}}
$$

where, $D\left(=1-\rho_{0} / \rho\right)$ is the mobile dislocation damage, $\rho_{0}$ is the initial dislocation density and $\rho$ the current dislocation density. $C_{d}$ is the material constant.

\section{Ductile Type Damage}

Under the condition of plastic deformation of metals the ductile damage takes place throughout three stages: void nucleation, growth and coalescence (Rice and Tracey, 1969). During cold forming the mechanism of deformation is the multiplication of dislocations since grain boundary sliding does not occur (Rice and Tracey, 1969). The result is voids nucleation around the second phase and typically inside the grain. A stress free surface on the voids is resulted, as the voids have been nucleated, through DE cohesion or cracking of the second phase/ inclusions, a stress free surface on the voids is resulted. In addition, the weakened material displays areas of localized stress and strain concentrations (Tvergaard, V. \& Needleman, A., 2001).

Rice and Tracey, (1969), proposed mathematical model for the growth of isolated spherical void under a triaxiality stress state [29, 30].

$$
\mathrm{D}=\int \frac{1}{1.65} \exp \left(\frac{3 \sigma_{\mathrm{H}}}{2 \sigma_{\mathrm{eq}}}\right) \mathrm{d} \varepsilon_{\mathrm{eq}} \text {, accepted for } \frac{\sigma_{\mathrm{H}}}{\sigma_{\mathrm{eq}}}>\frac{1}{3} \text { triaxiality }
$$

where $\sigma_{\mathrm{eq}}$ and $\varepsilon_{\mathrm{eq}}$ are the equivalent stress and strain.

For uniaxial tension state $\sigma_{2}, \sigma_{3}=0, \sigma_{\mathrm{H}}=\frac{\sigma_{1}}{3}$ and $\sigma_{\mathrm{eq}}=\sigma_{1}$, Damage becomes: 


$$
\mathrm{D}=\int \mathrm{d} \varepsilon_{\mathrm{eq}}
$$

So critical damage value at fracture is:

$$
\mathrm{D}_{\mathrm{C}}=\varepsilon_{\mathrm{eq}, \mathrm{f}}
$$

Gurson-Tvergaard-Needleman, established model for ductile failure predicts fracture by micro void nucleation and growth through plastic deformation condition [26, 31].

$$
\varphi=\frac{\Sigma^{2}}{\sigma_{0}{ }^{2}}+2 \mathrm{f}^{*} \mathrm{q}_{1} \cosh \left[\frac{3 \mathrm{q}_{2} \sum \mathrm{m}}{2 \sigma_{0}}\right]-\left(1+\mathrm{q}_{3} \mathrm{f}^{* 2}\right)=0, \text { where } \mathrm{q}_{3}=\mathrm{q}_{1}{ }^{2}
$$

where $\sum$ and $\sum m$ the von mises stress and hydrostatic stress; $q_{1,2,3}$ are model parameter depend on strain hardening properties

$q_{1}=1.5, q_{2}=1, q_{3}=2.25$ better values for plain strain condition (Tvergaard 1981, 1982), $\mathrm{f}$ is the void volume fracture, and $\sigma_{0}$ is the yield strength. $\mathrm{f}^{*}$ the modified damage parameter (taking account of the accelerated process of coalescence after reaching critical void volume fraction, $\mathrm{f}_{\mathrm{c}}$ (Tvergaard 1981; Needleman).

Mc Clintock proposed in 1968 a mathematical model assuming that material divided to fourfold elements containing oval cylindrical voids [30].

$$
\mathrm{I}_{\mathrm{b}}=\int_{0}^{\bar{\varepsilon}^{\mathrm{pf}}}\left\{\frac{\sqrt{3}}{2(1-\mathrm{n})} \sinh \left[\frac{\sqrt{3}}{2}(1-\mathrm{n}) \frac{\sigma_{\mathrm{a}}+\sigma_{\mathrm{b}}}{\sigma_{\mathrm{eq}}}\right]+\frac{3}{4}\left(\frac{\sigma_{\mathrm{a}}-\sigma_{\mathrm{b}}}{\sigma_{\mathrm{eq}}}\right)\right\} \mathrm{d} \bar{\varepsilon}^{\mathrm{p}}
$$

where $\bar{\varepsilon}^{\mathrm{p}}, \bar{\varepsilon}^{\mathrm{pf}}$ are the equivalent plastic strain and equivalent plastic strain at fracture, $\mathrm{n}$ is the exponent in the constitutive law

$$
\sigma_{\mathrm{y}}=\sigma_{\mathrm{y}_{0}}\left(\varepsilon_{0}+\varepsilon^{\mathrm{p}}\right)^{\mathrm{n}}
$$

$\sigma_{\mathrm{a}}, \sigma_{\mathrm{b}}$ may take as principle stresses

Brozzo et al. (see ref. [30]) proposed a criterion based on the fact that with hydrostatic stress increase the ductility greatly decreased (diminish) and fracture initiate due to maximum principle stress:

$$
\mathrm{I}_{\sigma_{1}, \sigma_{\mathrm{H}}}=\int_{0}^{\bar{\varepsilon}^{\mathrm{pf}}} \frac{2 \sigma_{1}}{3\left(\sigma_{1}-\sigma_{\mathrm{H}}\right)} \mathrm{d} \bar{\varepsilon}^{\mathrm{p}}
$$

$\sigma_{1}, \sigma_{\mathrm{H}}$ are the maximum principle stress and the hydrostatic stress, where $\bar{\varepsilon}^{\mathrm{p}}, \bar{\varepsilon}^{\mathrm{pf}}$ are the equivalent plastic strain and equivalent plastic strain at fracture.

\section{Superplastic Type Damage}

High temperature causes grain boundary diffusion, which facilitates grain rotation and grain boundary sliding, both of which are more active when the grain size is small, temperature is high and deformation rate is low, as in superplastic forming (Lin et al. $[24,25])$. However, grain rotation and boundary sliding are not restricted to these conditions and may be present to a lesser extent at faster forming rates and in alloys not capable of super plasticity. The relative displacement of grains resulting from 
rotation and boundary sliding is accommodated by the redistribution of matter within the mantle adjacent to grain boundaries (Lin et al. [25]). When this accommodating process is insufficient to meet the requirements of the deformation rate, stresses at the grain boundaries are not relaxed sufficiently and, consequently, cavities nucleate primarily at the triple point of the grain. When a cavity is present at a grain boundary (either nucleated during superplastic deformation or existing prior to the deformation), it grows by either superplastic diffusion processes or plastic deformation [25].

Nicolaou and Semiatin [32] have developed a mathematical model for superplastic and general hot deformation processes. The damage growth in tension has been modeled through the classic plasticity mechanisms resulting in an equation describing the variation of damage radius $r$ with strain,

$$
\mathrm{r}_{\mathrm{d}}=\mathrm{r}_{\mathrm{do}} \exp \left(\frac{\eta}{3} \varepsilon\right)
$$

where $\eta$ is an individual (volumetric) damage cavity parameter and $r_{d 0}$ is the initial cavity radius.

Pilling and Ridley (See Ref. [32]) investigate experimentally the influence on the cavity growth rate by hydrostatic pressure for superplastic alloys and they introduce the following equation.

$$
\eta^{\mathrm{ts}}=\eta\left(1+2 \frac{\mathrm{p}}{\bar{\sigma}}\right)
$$

where $\mathrm{p}$ is the hydrostatic pressure (whith a negative sign for compresive and postive for tensile)

$$
\frac{\mathrm{p}}{\bar{\sigma}}=\frac{\sigma_{\mathrm{m}}}{\bar{\sigma}}-\frac{1}{3}
$$

So the equation becomes

$$
\eta^{\mathrm{ts}}=\eta\left(\frac{1}{3}+2 \frac{\sigma_{\mathrm{m}}}{\bar{\sigma}}\right)
$$

$\eta$ is the cavity growth rate of an individual cavity, $\bar{\sigma}$ is effective stress, $\sigma_{m}$ is mean stress.

\section{CONCLUSION}

It is obvious that magnesium sheet alloys introduce an important mechanical property (strength/weight ratio), which is the major demand in automotive, aerospace and many modern industries. The forming of $\mathrm{Mg}$ sheets provides a suitable manufacturing process for complex component with high surface quality and favorable mechanical properties. Unfortunately the $\mathrm{Mg}$ sheets have a very poor formability in room temperature as revealed by the Forming Limit Diagram for a commercial Mg sheets. However the forming of magnesium at higher temperature gives the required ductility for conducting higher forming limits processes. The forming temperature from $200^{\wedge} \mathrm{C}$ to $300^{\wedge} \mathrm{C}$ provides an appropriate forming limits, usually Mg sheets formed at this range. Understanding magnesium behavior under different temperature condition and 
the material failure mechanism gives the chance to efficiently utilize $\mathrm{Mg}$ alloys in modern industries.

\section{REFERENCES}

[1] F. Zarandi and S. Yue, "Magnesium Sheet; Challenges and Opportunities", Magnesium Alloys - Design, Processing and Properties, January, (2011).

[2] T. Mukai, H. Watanabe, K. Ishikawa, K. Higashi, "Guide for Enhancement of Room Temperature Ductility in Mg Alloys at High Strain Rates", Materials Science Forum, Vol. 419-422, pp.171-176,Mar.(2003).

[3] Keeler S. P., "Determination of forming limits in automotive stampings", Sheet Met. Ind., 42 pp.683-91, (1965).

[4] Goodwin G. M., "Application of strain analysis to sheet metal forming problems in the press shop", Metall. Italiana, vol.60, pp. 764-74, (1968).

[5] H. Fatmaoui, R. Mesrar, J. Chaoufi, "Intrinsic diagram of sheet metal forming limits for arbitrary strain paths", J. of Materials: Design and applications, vol.222(4),pp.223-229, (2008).

[6] F. Djavanroodi, A. Derogar, "Experimental and numerical evaluation of forming limit diagram for Ti6Al4V titanium and Al6061-T6 aluminum alloys sheets", Materials \& Design, Vol 31, pp. 4866-4875, December (2010)

[7] M. A. Kröhn, S. B. Leen, T. H. Hyde, "A superplastic forming limit diagram concept for Ti-6Al-4V", J. of Materials: Design and Applications, vol.221 (4), pp.251-264, (2007).

[8] G. Palumbo, D. Sorgente, L. Tricarico, A numerical and experimental investigation of AZ31 formability at elevated temperatures using a constant strain rate test, Materials \& Design, Vol 31, pp. 1308-1316, March (2010).

[9] C. Vallellano, D. Morales \& F. J. García-Lomas, "A Study to Predict Failure in Biaxially Stretched Sheets of Aluminum Alloy 2024-T3", Materials and Manufacturing Processes, vol.23(3), pp.303-310, (2008).

[10] W. Wang, L. Huang, K. Tao, S. Chen, X. Wei, "Formability and numerical simulation of AZ31B magnesium alloy sheet in warm stamping process", Materials \& Design, Vol. 87,pp. 835-844,15 December (2015).

[11] A.R. Antoniswamy, A.J. Carpenter, J.T. Carter, L.G. Hector Jr., and E.M. Taleff, "Forming-Limit Diagrams for Magnesium AZ31B and ZEK100 Alloy Sheets at Elevated Temperatures", Journal of Materials Engineering and Performance, Vol. 22, pp. 3389-3397 June 22, (2013).

[12] L.C. Chan \& X.Z. Lu, "Material sensitivity and formability prediction of warmforming magnesium alloy sheets with experimental verification" The International Journal of Advanced Manufacturing Technology, Vol. 71, pp. 253-262, (2013).

[13] ISO 12004-2:2008. Metallic Materials - Sheet and Strip - Determination of Forming Limit Curves - Part 2: Determination of Forming Limit Curves in Laboratory, ISO/TC 164/SC 2.

[14] H.J. Kim, S.C. Choi, K.T. Lee and H.Y. Kim, "Experimental Determination of Forming Limit Diagram and Spring back Characteristics of AZ31B Mg Alloy Sheets at Elevated Temperatures", Material Transactions, Vol. 49, No. 5, pp. 1112-1119, (2008). 
[15] W. Lingyun, L. Zhiwen, Z. Yazhong, Q. Xiaogang, "The Formability of AZ31B Magnesium Alloy Sheet", Journal of Wuhan University of Technology, June (2006).

[16] G. Ambrogio, C. Bruni, S. Bruschi, L. Filice, A. Ghiotti4, M. Simoncini, "Characterization of AZ31B magnesium alloy formability in warm forming conditions", International Journal of Material Forming, Vol. 1, pp. 205-208, April (2008).

[17] C. Bruni, A. Forcellese, F. Gabrielli, M. Simoncini, "Effect of temperature, strain rate and fiber orientation on the plastic flow behaviour and formability of AZ31 magnesium alloy", Journal of Materials Processing Technology, Vol. 210, 1, pp. 1354-1363 July (2010).

[18] S. Kurukuri, M. J. Worswick, D. G. Tari, R. K. Mishra, J. T.Carter, "Rate Sensitivity and Tension-Compression Asymmetry in AZ31B Magnesium Alloy Sheet", Phil. Trans. A, 7 April (2014).

[19] M. Boba, C. Butcher, N. Panahi, M.J. Worswick, R.K. Mishra, J.T. Carter, "Warm forming limits of rare earth-magnesium alloy ZEK100 sheet", International Journal of Material Forming, (2015).

[20] M. Boba, "Warm Forming Behaviour of ZEK100 and AZ31B Magnesium Alloy Sheet", UWSpace, (2014).

[21] M. S. Kamel, "An investigation of hot forming quench process for AA6082 aluminium alloys", PHD, Thesis, Imperial College London, (2010).

[22] J. Lin, D.R. Hayhurst, B.F. Dyson, "A new design of uniaxial creep testpiece with slit extensometer ridges for improved accuracy of strain measurement, International Journal of Mechanical Sciences", Vol. 35, pp. 63-78, (1993).

[23] E.C. Ching Hsu, "Effect of Deformation Conditions on Texture and Microstructure of Magnesium Sheet AZ31", eScholarship_McGill, (2006).

[24] J.Lin, Y. Liu, T. A. Dean., "A Review on Damage Mechanisms, Models and Calibration Methods under Various Deformation Conditions", In. J. of Damage Mechanics,vol .14, pp.299-319, (2005).

[25] J .Lin, Z.L. Kowalewski, J. Cao, "Creep rupture of copper and aluminium alloy under combined loadings-experiments and their various descriptions", Int. J. Mech. Sci, vol.47, pp.1038-1058, (2005).

[26] J. Lemaitre and R. Desmorat, "Engineering Damage Mechanics Ductile, Creep, Fatigue and Brittle Failures", Springer Science \& Business Media, Jan 16, (2006).

[27] H.T. Yao, F.Z. Xuan, Z. Wang, S.Tung Tu, "A review of creep analysis and design under multi-axial stress states", Nuclear Engineering and Design, Vol. 237, pp. 1969-1986, October (2007).

[28] A.C.F. Cocks and M.F. Ashby, "Creep Fracture by Void Growth", International Union of Theoretical and Applied Mechanics, pp. 368-387.

[29] B.C. Simonsen, R. Tornqvist, "Experimental and numerical modeling of ductile crack propagation in large-scale shell structures", Marine Structures, Vol. 17, pp. 1-2, (2004).

[30] C. Zheng, J.M.A. Ceasar DE SA, F.M. Andrade Pires, "A Comparison of Models for Ductile Fracture Prediction in forging Processes", Computer Methods in Materials Science ,Vol. 7, No. 4 , PP.389-396, (2007).

[31] S. Hao, W. Brocks, "the Gurson-Tvergaard-Needleman-model for rate and temperature-dependent materials with isotropic and kinematic hardening", Computational Mechanics, Vol. 20, pp. 34-40, (1997). 
[32] P.D. Nicolaou, S.L. Semiatin, "An experimental and theoretical investigation of the influence of stress state on cavitation during hot working", Acta Materialia, Vol.51, pp.613-623, (2003).

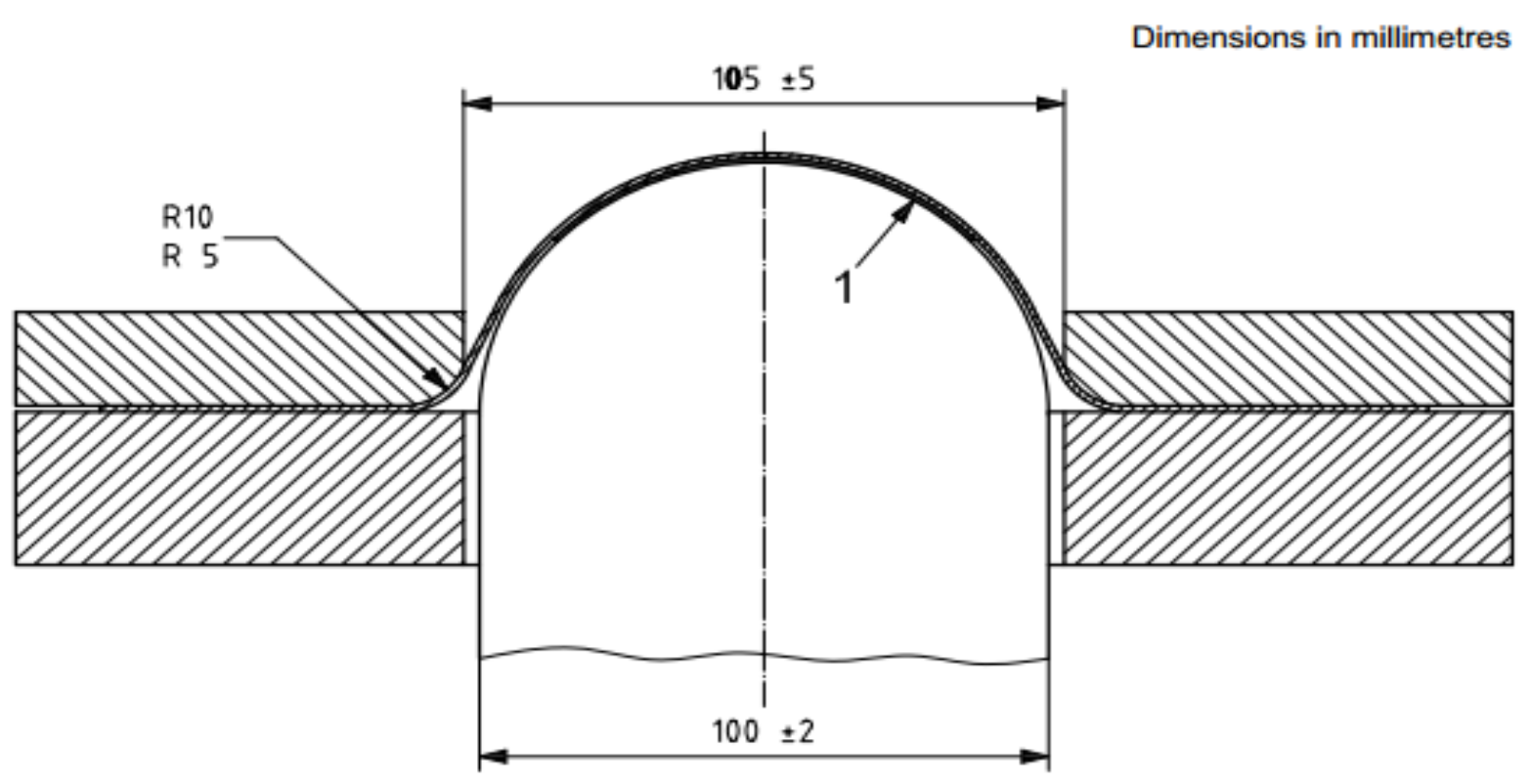

(a)

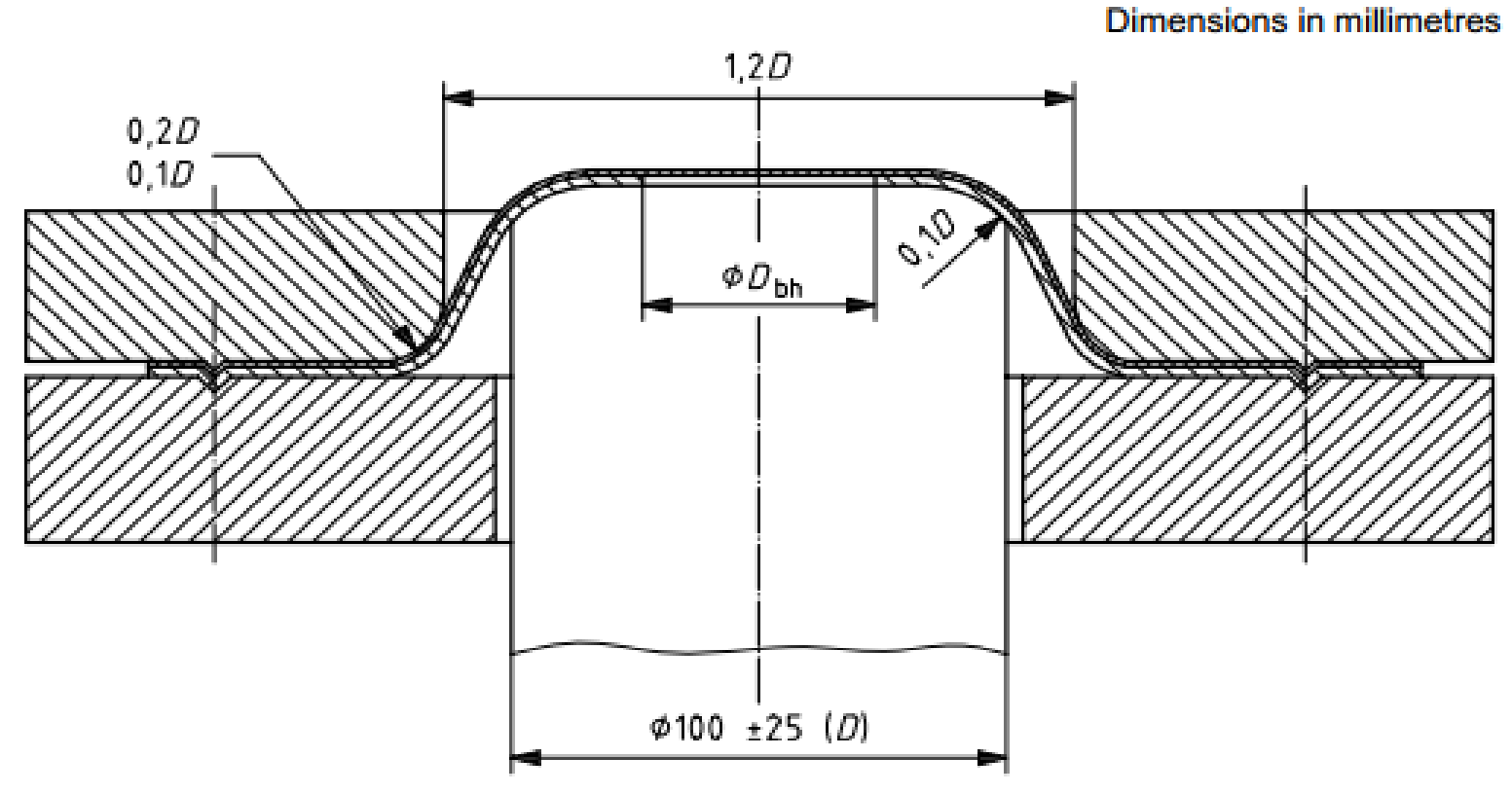

(b)

Fig.1. Illustration of the cross section of the tool used for (a) Nakajima testing,

(b) Marciniak test (ISO 12004-2:2008) [13]. 


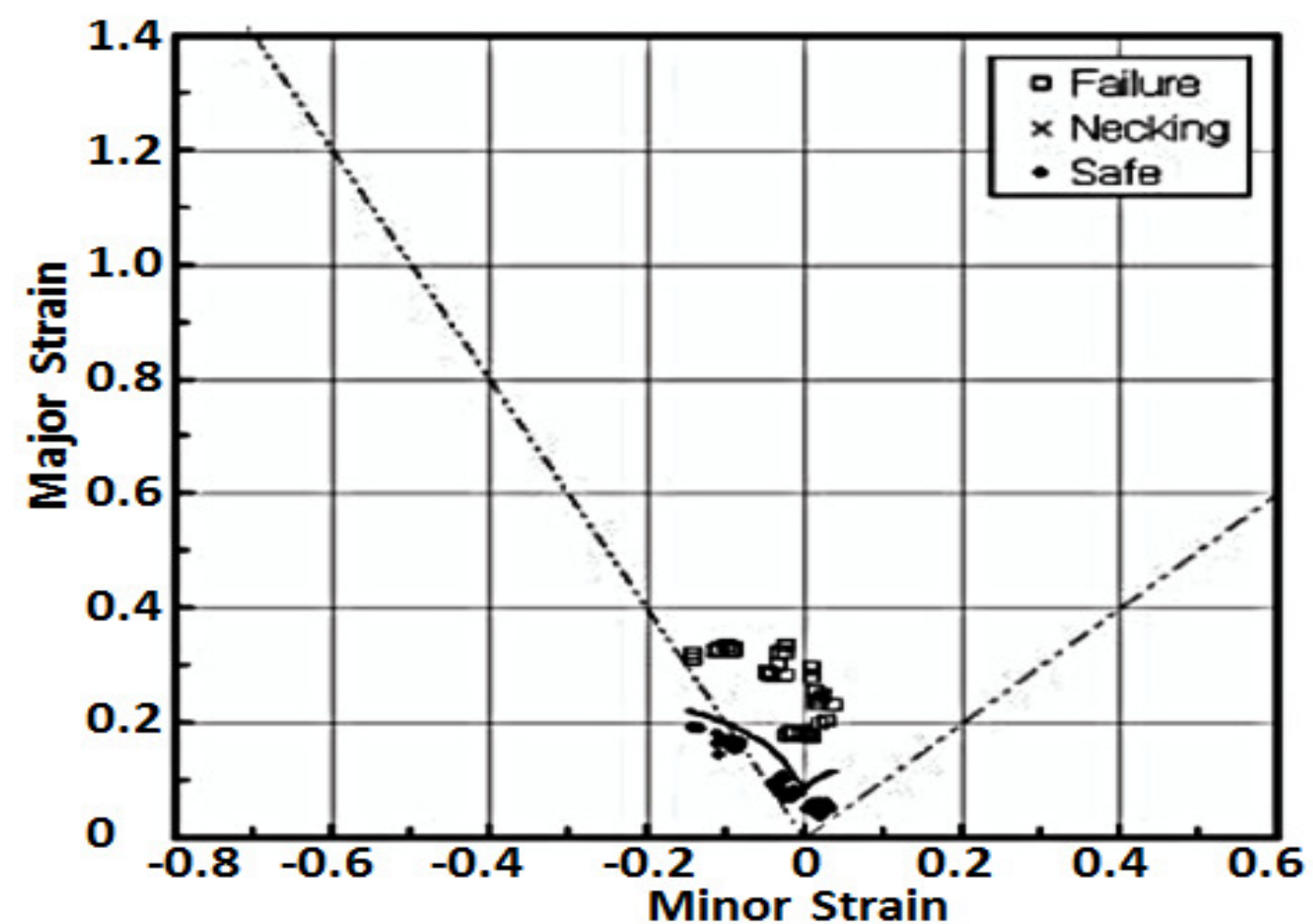

Fig.2. Experimental FLD at cold condition $25^{\circ} \mathrm{C}$ [14].

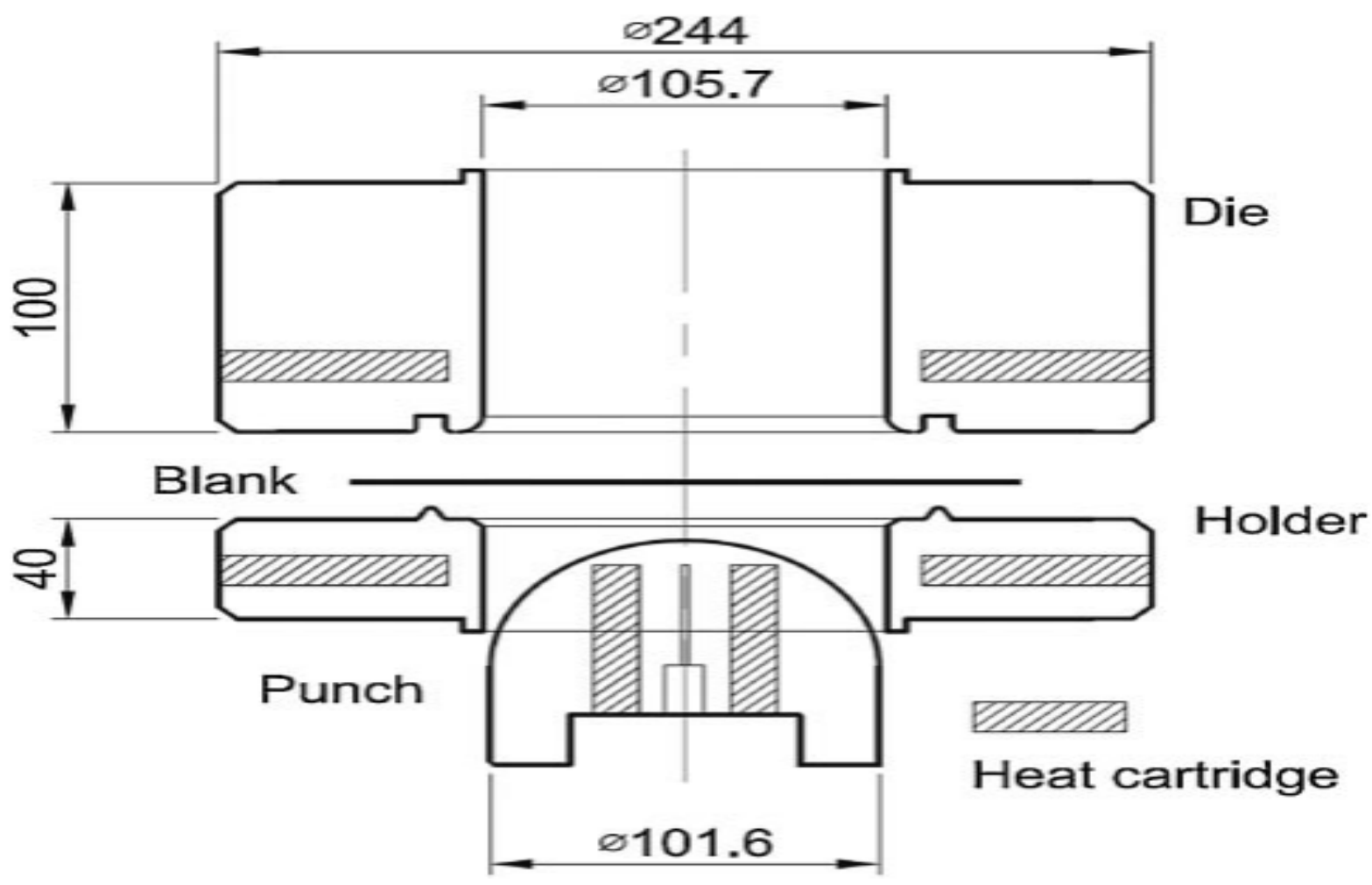

Fig.3. Geometry and dimension of FLD stretching test apparatus for FLC measurements [14]. 


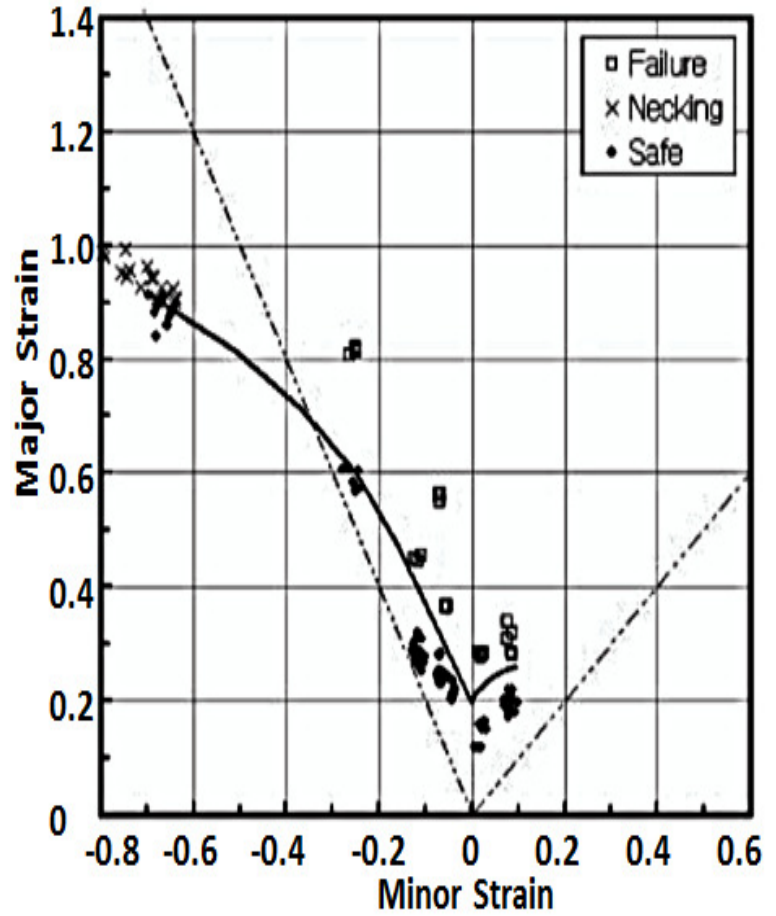

(a)

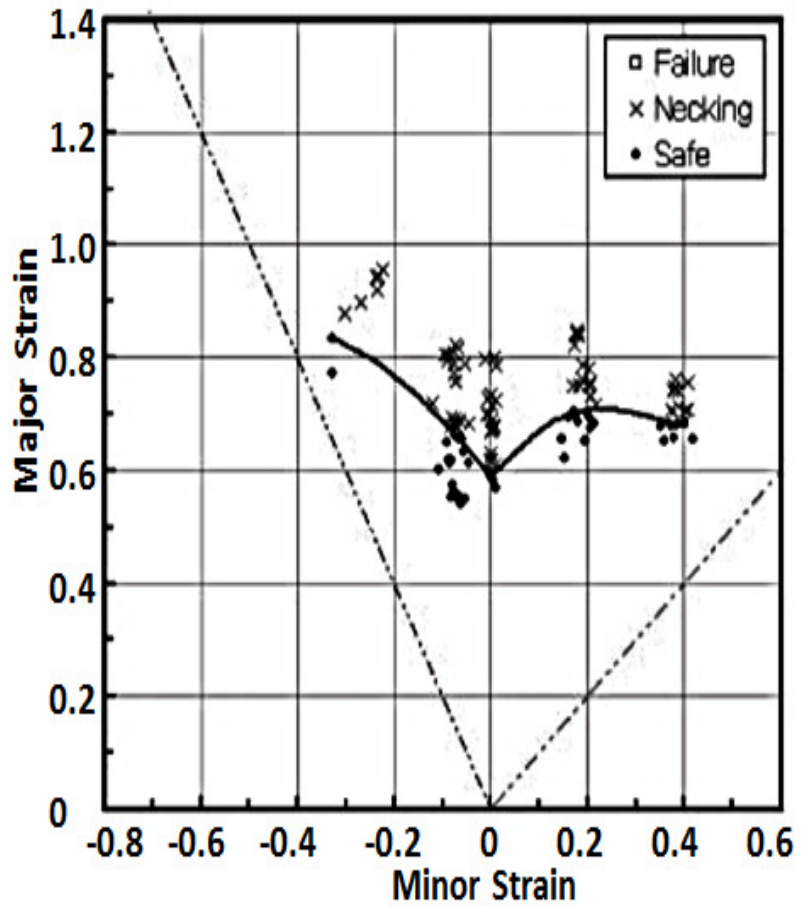

(b)

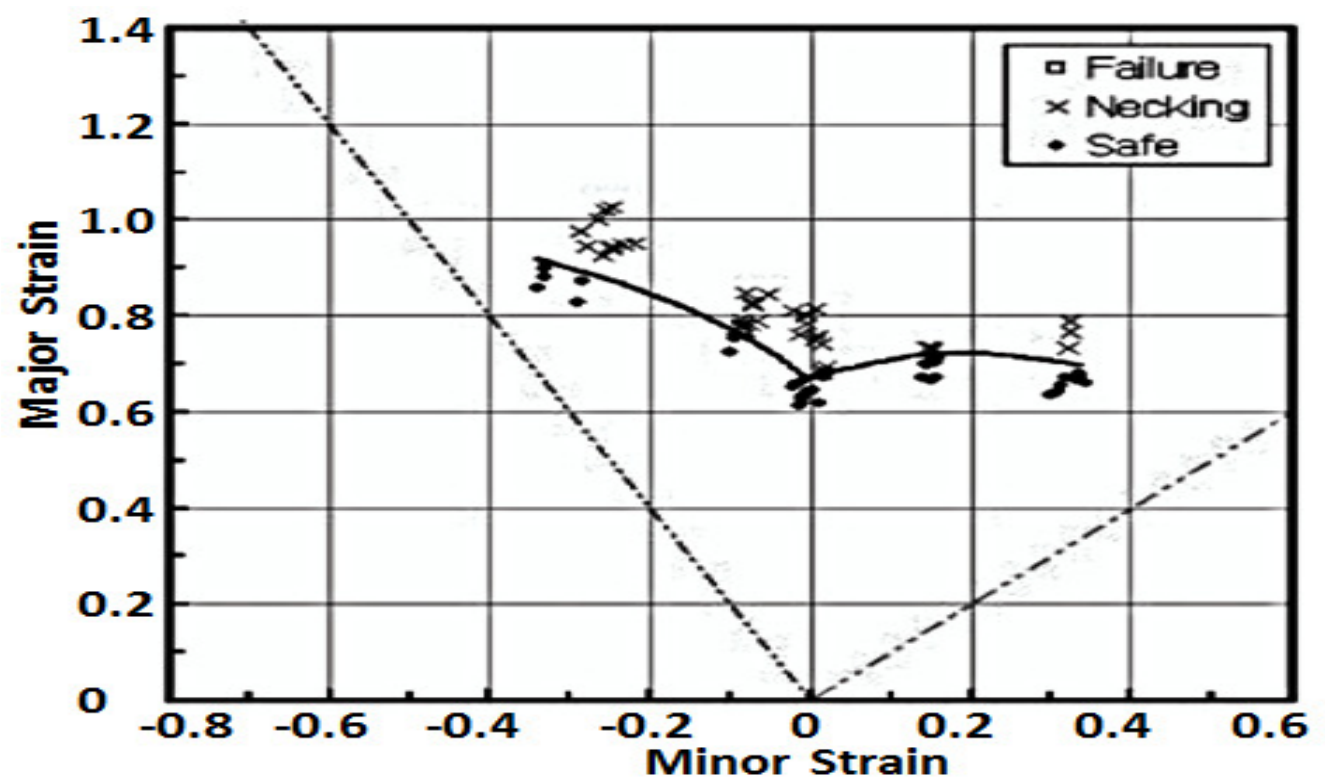

(c)

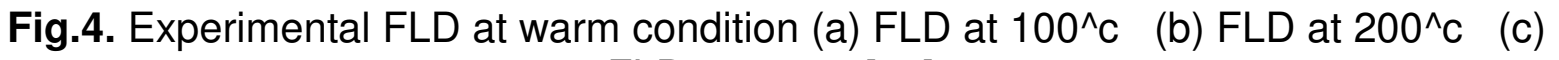
FLD at $250^{\wedge} \mathrm{c}[14]$. 


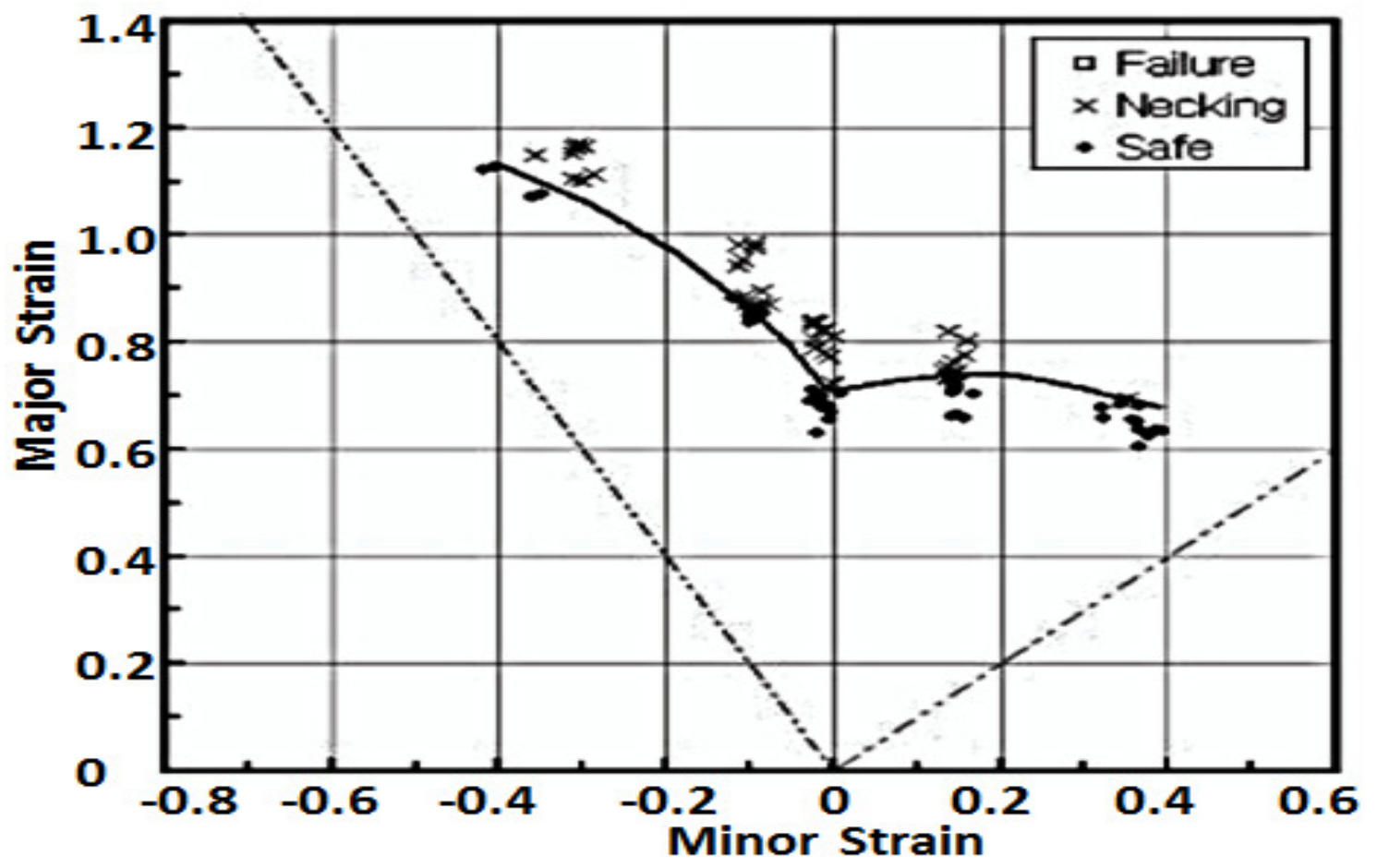

Fig.5. Experimental FLD at hot condition at $300^{\wedge} \mathrm{C}[14]$.

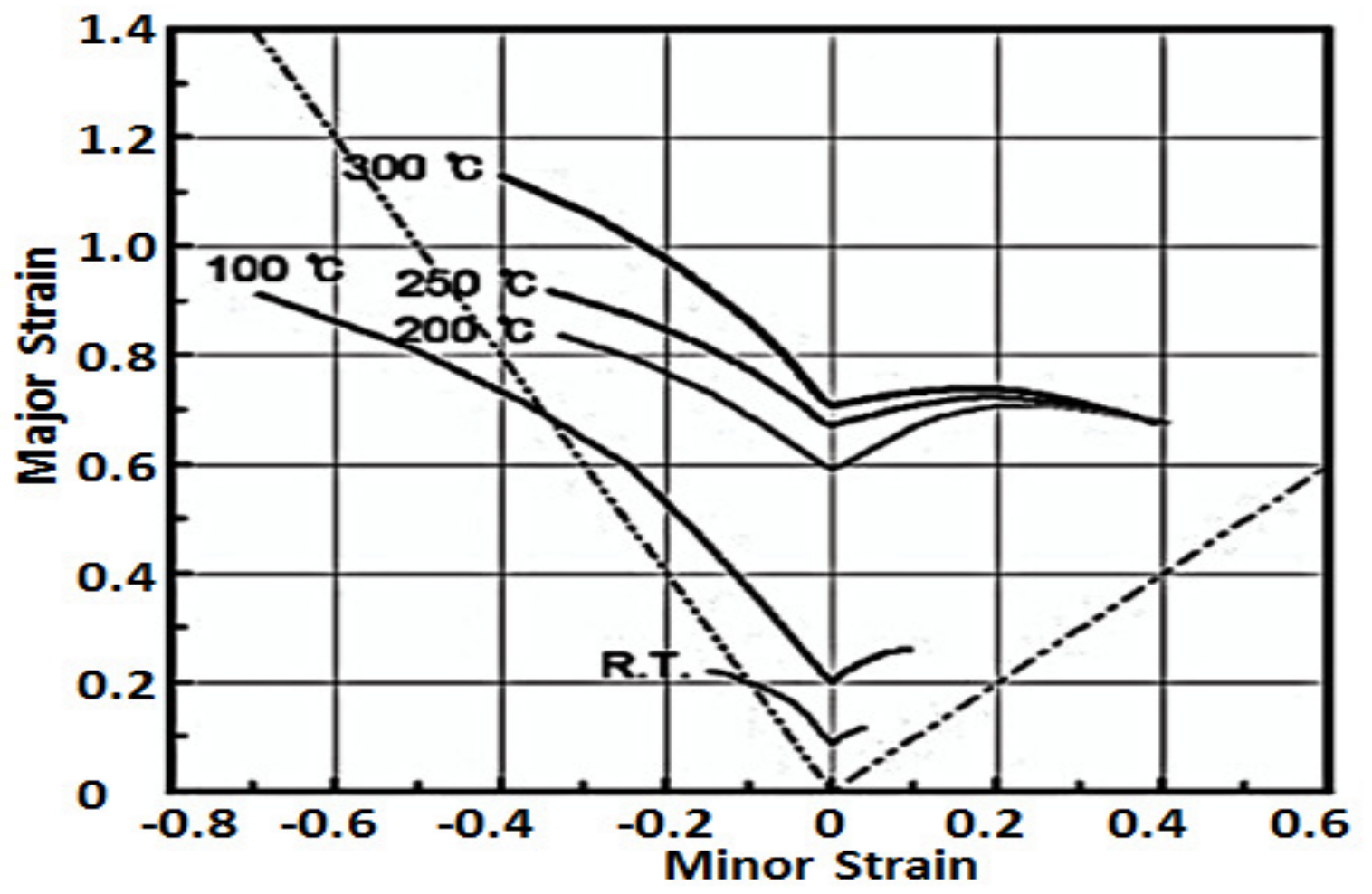

Fig.6. FLD for different temperature [14]. 


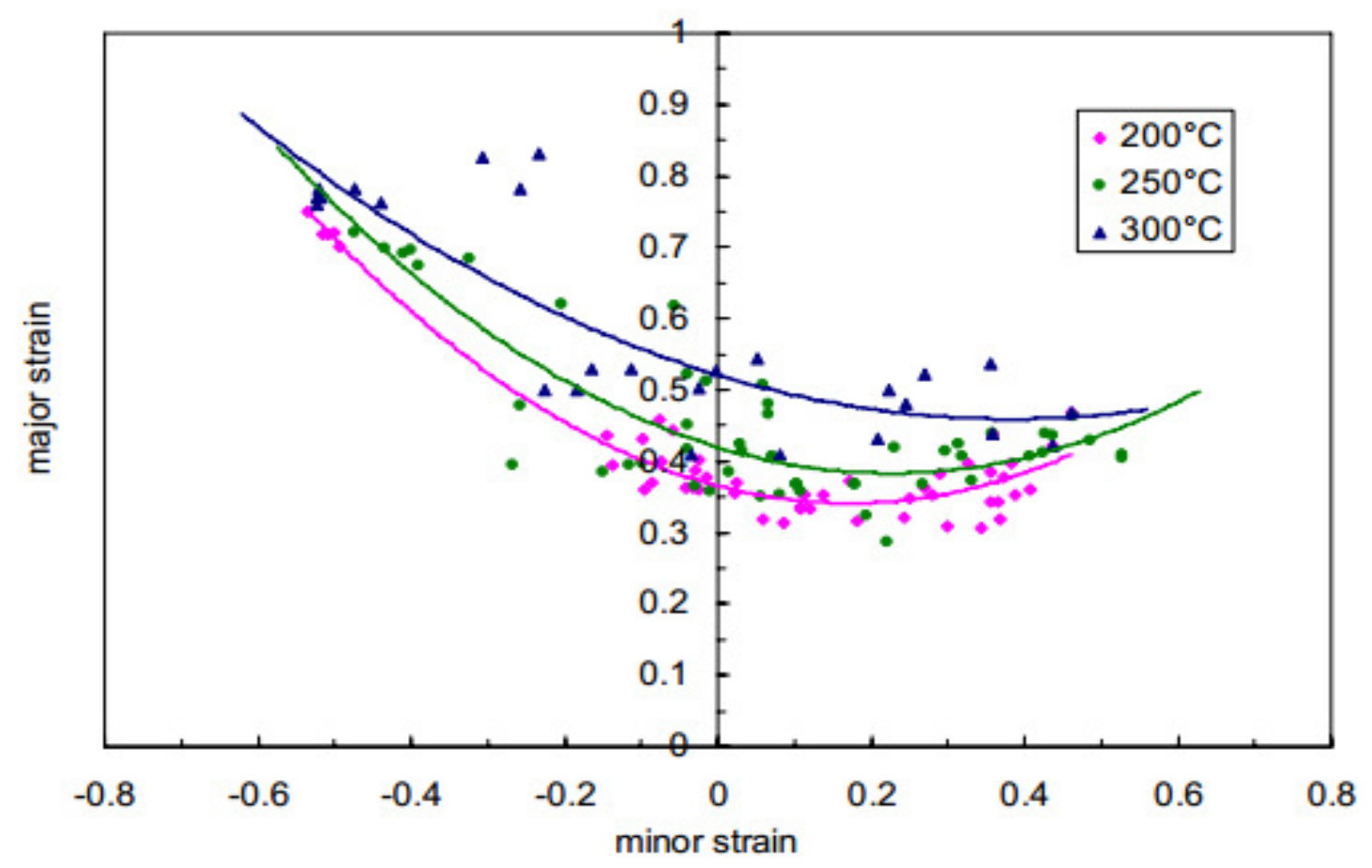

Fig.7. Effect of temperature on the FLDs $(\mathrm{v}=0.1 \mathrm{~mm} / \mathrm{s})$ [16].

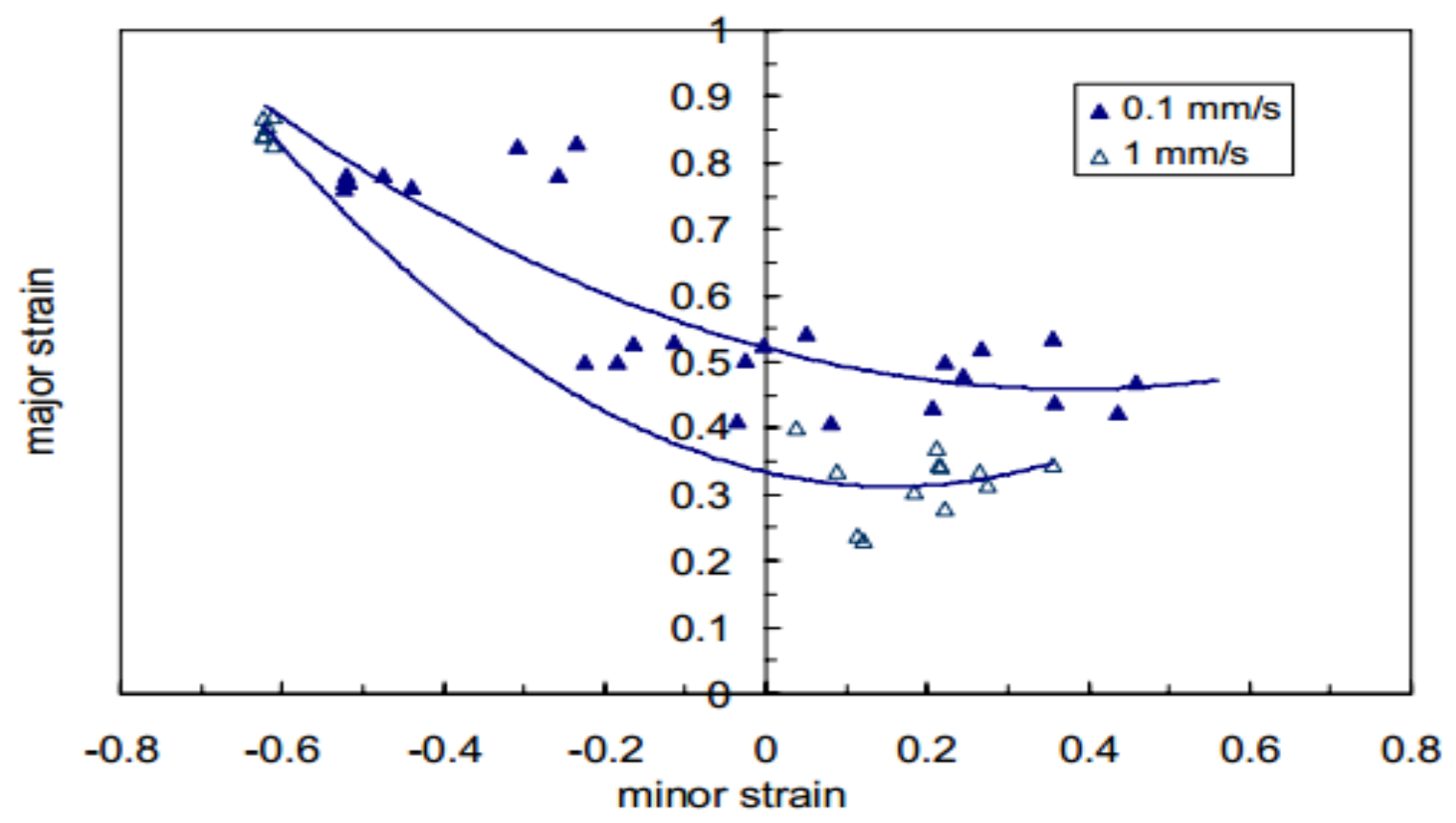

Fig.8. Effect of punch speed on the FLDs $\left(T=300^{\circ} \mathrm{C}\right)[16]$. 


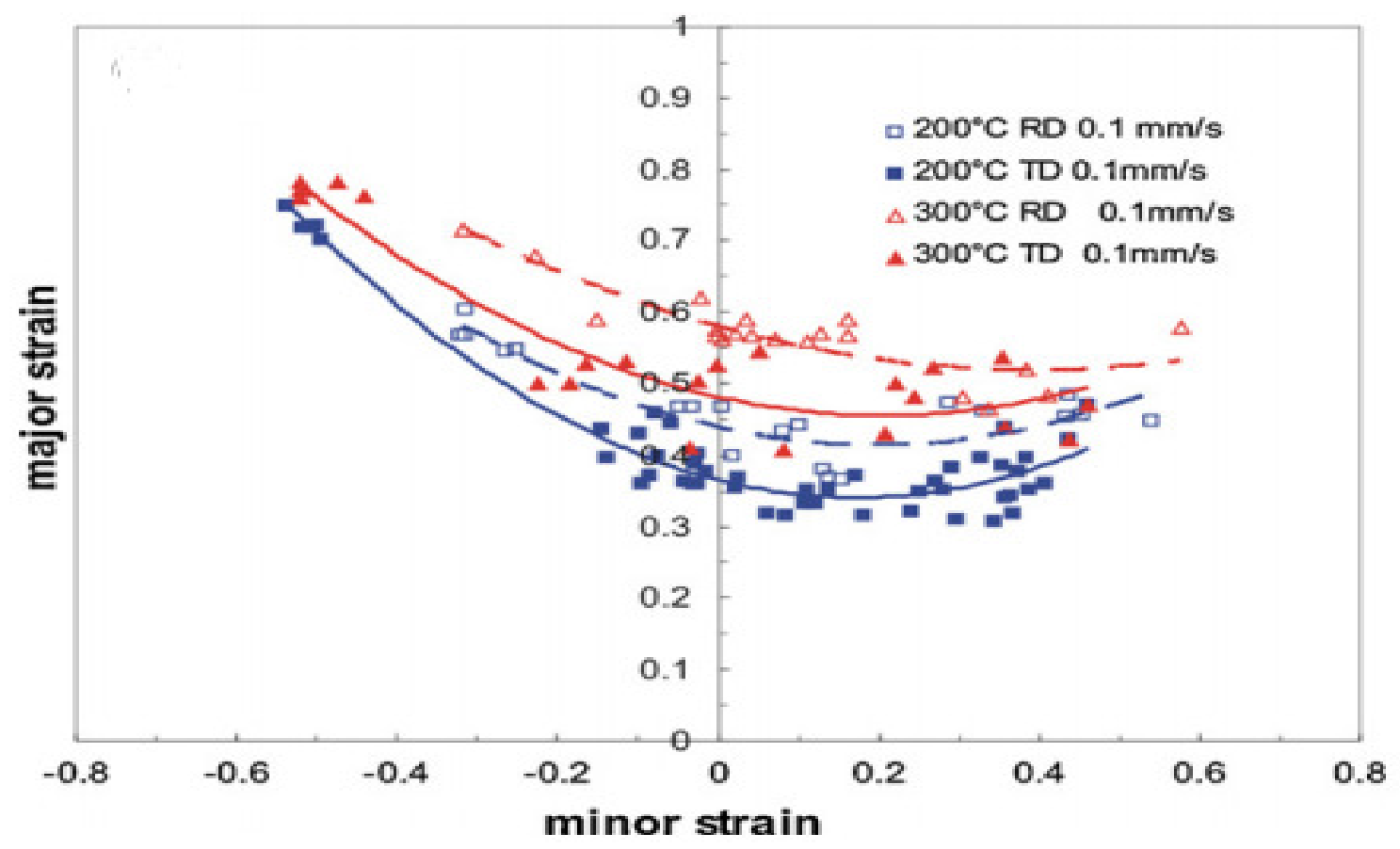

(a)

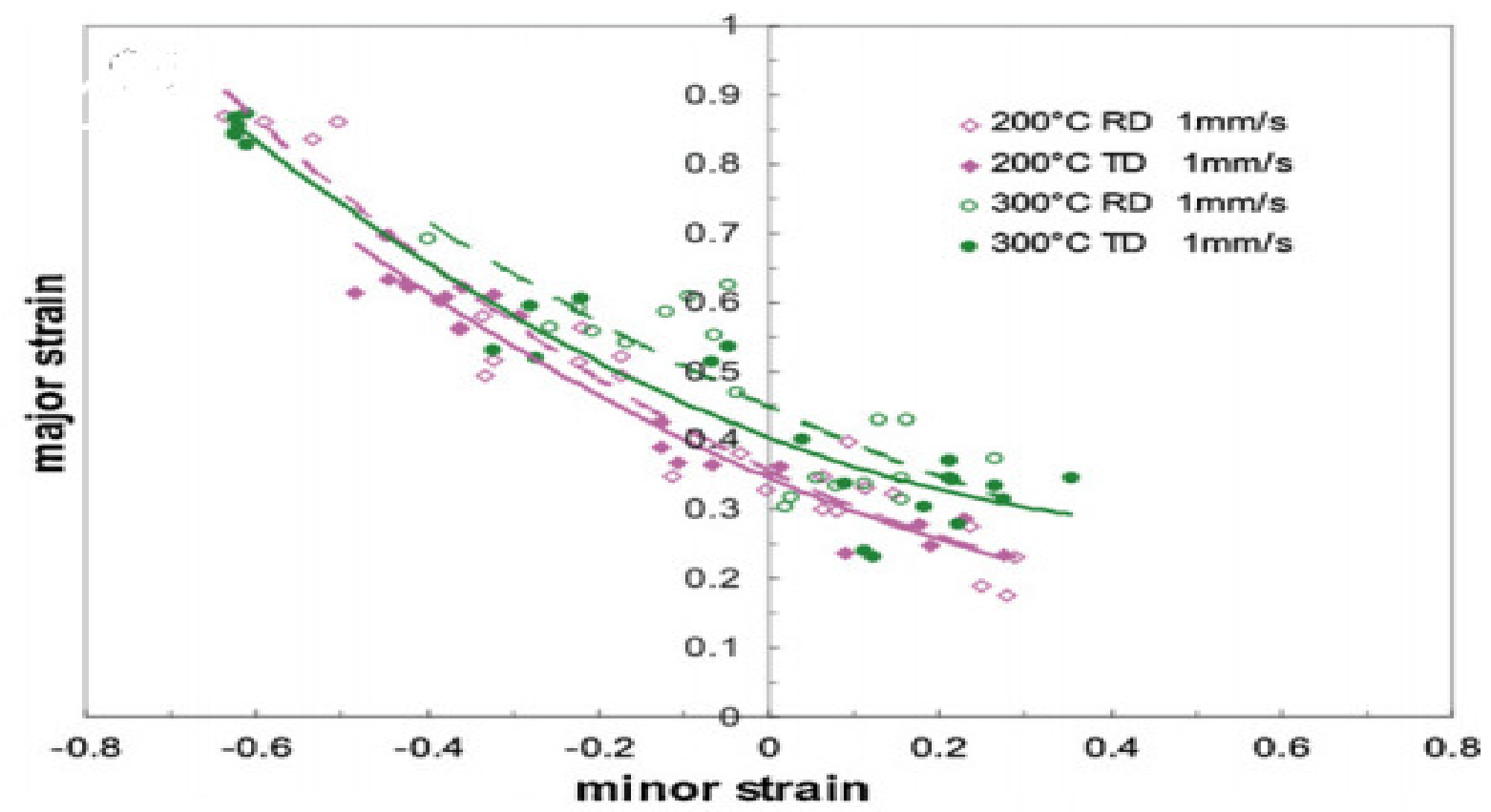

(b)

Fig.9. Effects of temperature and fiber orientation on the forming limit curves at different cross-head speeds: (a) $0.1 \mathrm{~mm} / \mathrm{s}$ and (b) $1 \mathrm{~mm} / \mathrm{s}$ [17]. 


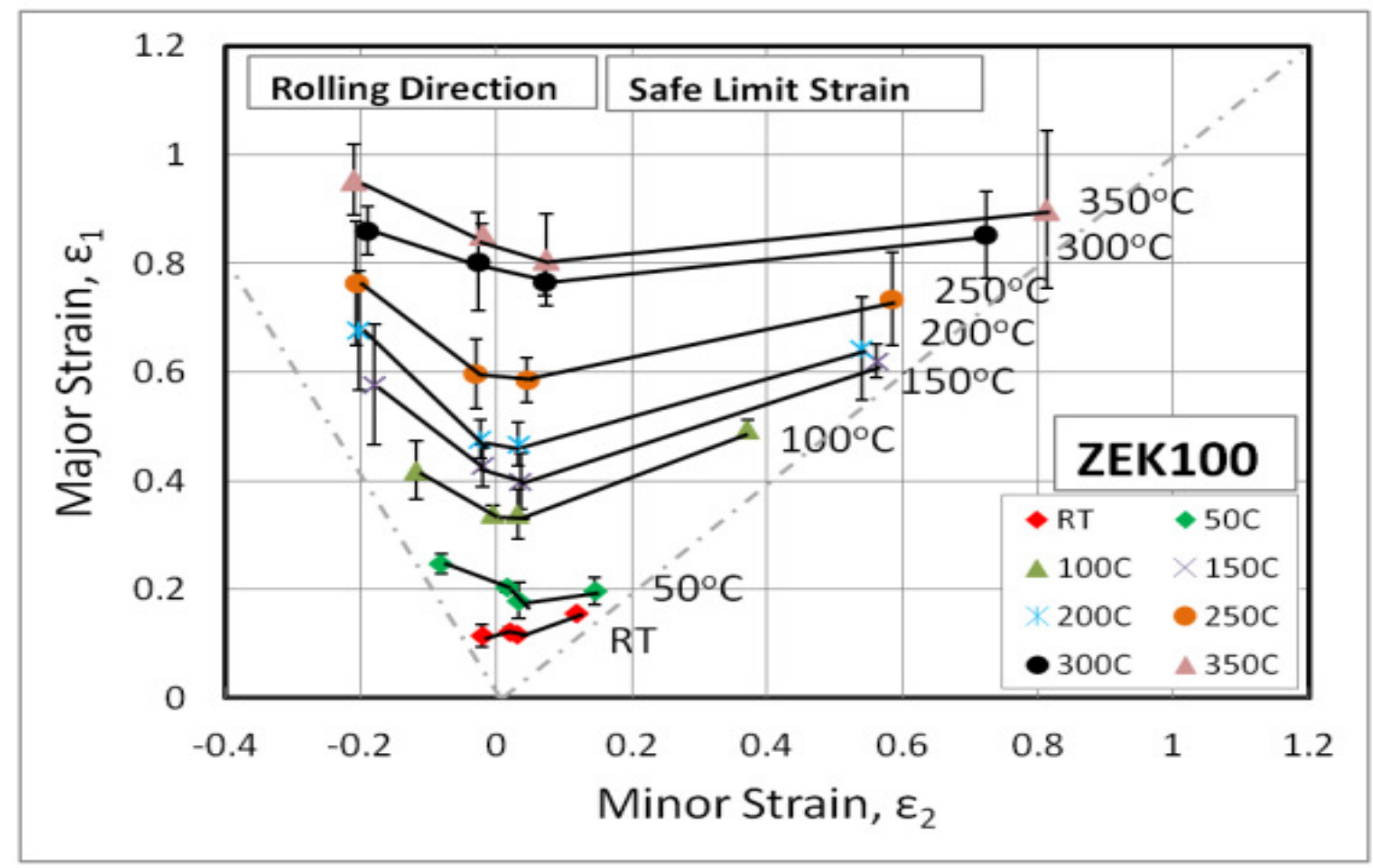

(a)

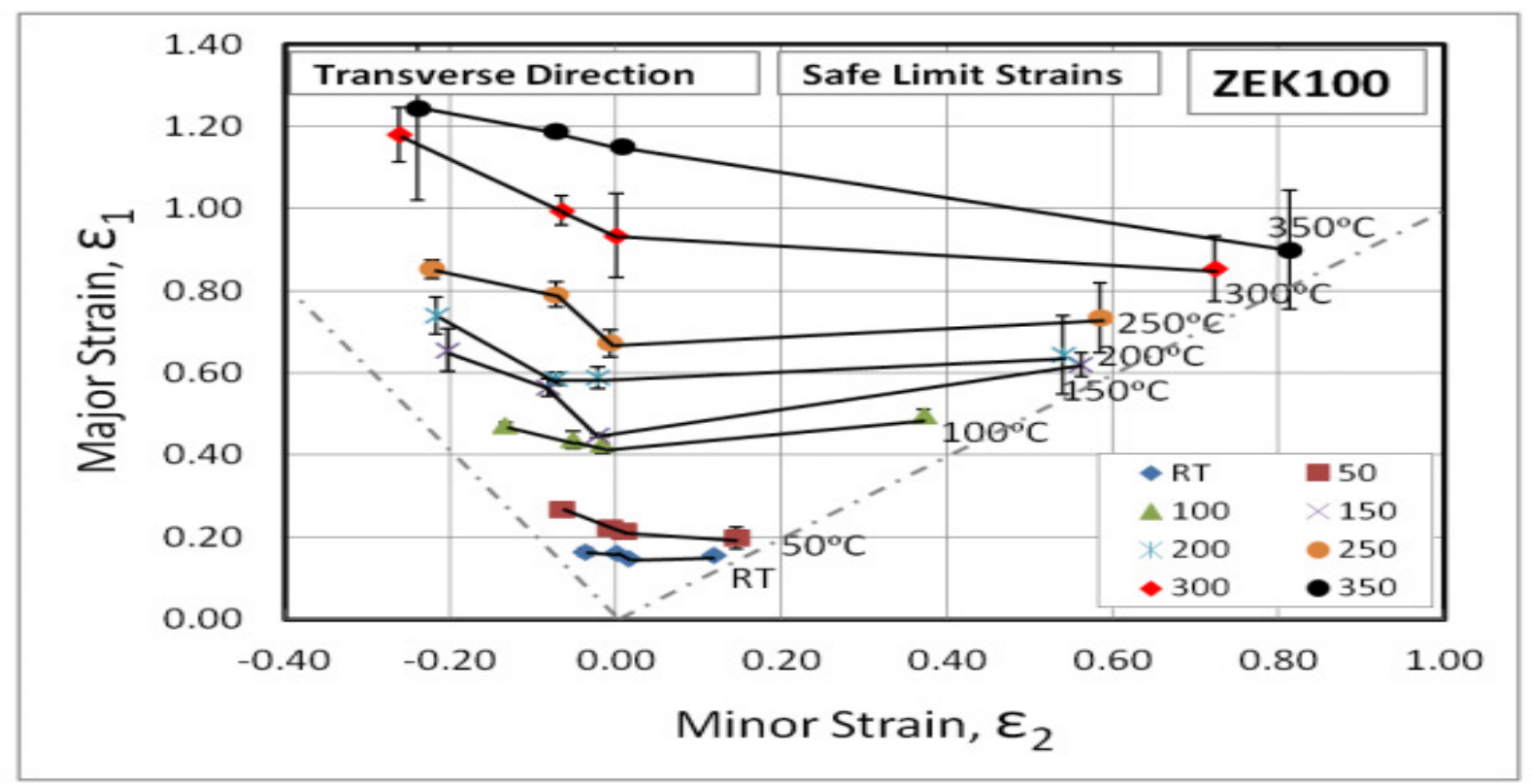

(b)

Fig.10. FLD for ZEK100 at temperatures from 25 to $350{ }^{\circ} \mathrm{C}$ in the (a) rolling direction (b) transverse direction [20]. 